Article

\title{
Analysis of Spatial Variability and Influencing Factors of Soil Nutrients in Western China: A Case Study of the Daliuta Mining Area
}

\author{
Linli Long ${ }^{1,2} \mathbb{D}$, Ying Liu ${ }^{1,2, * \mathbb{D}}$, Xiaoyang Chen ${ }^{2,3}$, Junting Guo ${ }^{1}$, Xinhui Li $4 \mathbb{D}^{\mathbb{D}}$, Yangnan Guo ${ }^{5}$, Xuyang Zhang ${ }^{2}$ \\ and Shaogang Lei ${ }^{4}$
}

check for

updates

Citation: Long, L.; Liu, Y.; Chen, X.; Guo, J.; Li, X.; Guo, Y.; Zhang, X.; Lei, S. Analysis of Spatial Variability and Influencing Factors of Soil Nutrients in Western China: A Case Study of the Daliuta Mining Area. Sustainability 2022, 14, 2793. https:// doi.org/10.3390/su14052793

Academic Editors: Jeroen Meersmans and Rajan Ghimire

Received: 29 January 2022

Accepted: 25 February 2022

Published: 27 February 2022

Publisher's Note: MDPI stays neutral with regard to jurisdictional claims in published maps and institutional affiliations.

Copyright: (C) 2022 by the authors. Licensee MDPI, Basel, Switzerland. This article is an open access article distributed under the terms and conditions of the Creative Commons Attribution (CC BY) license (https:// creativecommons.org/licenses/by/ $4.0 /)$.
1 State Key Laboratory of Water Resource Protection and Utilization in Coal Mining, China Energy Investment, Beijing 102209, China; long6_6@163.com (L.L.); gitcumtb@163.com (J.G.)

2 School of Earth and Environment, Anhui University of Science and Technology, Huainan 232001, China; chenxy@aust.edu.cn (X.C.); zxy374260025@163.com (X.Z.)

3 Anhui Engineering Laboratory for Comprehensive Utilization of Water and Soil Resources \& Ecological Protection in Mining Area with High Groundwater Level, Anhui University of Science and Technology, Huainan 232001, China

4 Engineering Research Center of Ministry of Education for Mine Ecological Restoration, China University of Mining and Technology, Xuzhou 221116, China; xinhui.li@cumt.edu.cn (X.L.); lsgang@cumt.edu.cn (S.L.)

5 Shenhua Shendong Coal Group Co., Ltd., Technology Research Institute, Shenmu 719315, China; 10031311@chnenergy.com.cn

* Correspondence: liuying340825@aust.edu.cn

\begin{abstract}
An understanding of the spatial variation and influence factors of soil nutrients in mining areas can provide a reference for land reclamation and ecological restoration. Daliuta was used as the study area. The spatial variability of soil nutrients was analyzed using traditional statistics and geostatistics. The effects of topography, mining history, and soil erosion were discussed. The results indicate that the soil $\mathrm{pH}$ of the Daliuta mining area is slightly acidic to slightly alkaline, and the soil organic matter, available nitrogen, available phosphorus, and available potassium belonged to the five levels (very low), six (extremely low), five (extremely low), and four (moderately low), respectively. The soil water and salt content indicated that the soil environment in the mining area is arid and has normal levels of salinity. The organic matter, available nitrogen, available phosphorus, available potassium, and soil salt varied moderately, and the $\mathrm{pH}$ did not change much, while the soil water varied strongly. The organic matter, $\mathrm{pH}$, and soil salinity are moderately spatially autocorrelated, and the available nitrogen, available phosphorus, available potassium, and soil water are weakly spatially autocorrelated. Each nutrient index had a certain spatial trend effect. The slope, aspect, elevation, and topographic wetness index are the primary topographic factors that control the spatial distribution of soil nutrients. The organic matter, $\mathrm{pH}$, and soil salinity are moderately spatially autocorrelated, and the available nitrogen, available phosphorus, available potassium, and soil water are weakly spatially autocorrelated. Each nutrient index had a certain spatial trend effect. The slope, aspect, elevation, and topographic wetness index are the primary topographic factors that control the spatial distribution of soil nutrients. Soil erosion and mining history are also important factors that lead to the spatial variation of soil nutrients.
\end{abstract}

Keywords: Daliuta mining area; soil nutrients; geostatistical analysis; spatial variation; influence factors

\section{Introduction}

Land quality degradation is becoming a major environmental issue that faces the world owing to the activities of humans and climate fluctuations. Therefore, preventing land degradation is crucial to the protection of ecosystem services and human well-being. Coal is an important source of energy in China and accounts for approximately $70 \%$ of China's disposable energy consumption structure. In addition, $>95 \%$ of China's coal 
mining is conducted underground [1], which leads to a large area of land subsidence in the mining areas (MA), causing serious damage to the ecological environment. The coal resource development process will substantially damage the land. For example, excavation, occupation, and collapse, among others, not only significantly change the performance, composition, and structure of the ecological environmental elements but also seriously restrict the integrity of the ecosystem, thus inducing the degradation of mining land quality. Furthermore, the current energy focus of China has been transferred to the western provinces, which are located in arid and semiarid regions in which the ecological environment is fragile. Large-scale and intensive coal mining in these areas may cause more serious land degradation than that in the central and eastern regions.

Soil nutrients are important quantitative indicators used to measure the soil quality [2-4]. Research on soil nutrients outside of China primarily focuses on the carbon source/carbon sinks [5], vegetation restoration succession [6], degraded land reconstruction [7], and other aspects. The methods include remote sensing recognition and interpretation $[8,9]$, experiments to determine the soil physical and chemical properties [10], and soil degradation grading using some typical evaluation theories, such as the Global Assessment of Human-Induced Soil Degradation (GLASOD), Assessment of The Status of HumanInduced Soil Degradation in South and Southeast Asia (ASSOD), and Evaluation Method Proposed by The Russian Academy of Sciences (RUSSIA) [11]. The soil is divided into different types based on regional heterogeneity, combined with the causes, characteristics, and main manifestations of land degradation. The process of land nutrient degradation is complex. Although remote sensing monitoring can extract large-scale spatial distribution characteristics, the inversion accuracy of soil nutrient content is affected by the ground cover, and it is difficult to achieve precise spatial monitoring. The research on land degradation in MA within China typically focuses on factors, classification, investigation [12], or approximate soil quality, ecological health, and landscape scale, among others [13], and the use of $3 S$ technology to conduct larger-scale monitoring of land degradation [14,15]. It is rare to analyze the laws of soil physical and chemical properties and changes in quality in combination with the terrain changes around the mining area. It is unclear whether the soil properties affected by soil erosion and coal mining activities have similar characteristics with those of other degraded soils.

The degradation of soil nutrients is complex, regional, and dynamic, and the factors that lead to soil nutrient degradation are diverse. Human disturbance of various environmental factors and ecological processes of the ecosystem during coal mining may also cause the degradation of soil nutrients. Human disturbances affect the activities of soil microorganisms and enzymes, which, in turn, affect the degradation of plant/animal matter and the release of trace elements and nutrients, which results in a reduction in soil fertility [16]. The process of soil development can be affected by factors, such as parent material, climate, topography, soil management, land use, and man-made factors [17,18]. Soil nutrients have a high degree of universal spatial variability in physical, chemical, and biological properties [19-25]. The spatial distribution pattern of soil nutrients is a concrete manifestation of soil spatial heterogeneity [26]. In recent years, a large number of researchers within China and in other countries have applied geostatistics through GIS software to study the spatial heterogeneity of soil nutrients in different regions. Zhang et al. [27] used ordinary Kriging and cluster analysis to explore the spatial heterogeneity of available soil potassium in the hilly area of western Chongqing. Dai et al. [28,29] revealed the spatial heterogeneity of organic carbon, nitrogen, phosphorus, potassium, and $\mathrm{pH}$ in typical subtropical forest soils in Zhejiang based on spatial analytical methods, such as geostatistics and Moran's I index, and analyzed their influencing factors. Razan Malla [30] used GIS combined with ordinary Kriging interpolation to analyze the mechanical composition, $\mathrm{pH}$, soil organic matter, total nitrogen, available phosphorus, available potassium, and trace elements zinc and boron. Sharma and Sood [31] used a combination of data analysis and geostatistics to analyze the spatial variability of black soil fertility in central India. Santos et al. [32] used a combination 
of descriptive statistics and geostatistics to evaluate the spatial variability of soil fertility and its relationship with cocoa production.

The Daliuta MA is one of the extremely large mines of the Shendong Coal Group. It is located in an arid and semiarid area with a fragile ecological environment that is at the junction of Yulin City in Western Shaanxi Province and Ordos City in the Inner Mongolia Autonomous Region. The high-intensity and large-scale mining of coal resources in the mining area have led to a series of geological disasters, such as ground subsidence and landslides, and may also cause land degradation, primarily represented by soil erosion, vegetation degradation, and desertification among others [33]. Simultaneously, the slope fractures caused by mining are accompanied by a large number of ground fissures on the surface and severely disturb the soil quality in the MA.

The spatial variability of soil nutrients and their influencing factors are the basis for the protection and improvement of soil quality. However, most of the studies were conducted on soil samples with different properties, and therefore, they could not be used to comprehensively analyze the spatial distribution characteristics of soil properties or the impact of mining activities on soil properties. For a mining area that needs remediation, unclear spatial variation characteristics of soil moisture, salinity, and nutrients will increase the difficulty of artificially guiding restoration. Therefore, this paper uses the Daliuta MA as the research area and GIS and geostatistical analyses to analyze the spatial variability of soil $\mathrm{pH}$, soil organic matter (SOM), available nitrogen (AN), available phosphorus (AP), available potassium (AK), soil moisture, and soil salinity and explores the influence of topographical factors, mining history, and soil erosion on the spatial distribution of nutrients to provide a theoretical basis for land reclamation and ecological restoration in coal mining areas. These results should provide a way to rationally utilize land and sustainably develop mining areas.

\section{Materials and Methods}

\subsection{Description of the Study Area}

The Daliuta MA is located in part of Daliuta Town and Zhongii Town, Shenmu County, Yulin City, Shaanxi Province. The geographical coordinates are $39^{\circ} 13^{\prime} 53^{\prime \prime}-39^{\circ} 21^{\prime} 32^{\prime \prime}$ $\mathrm{N}, 110^{\circ} 12^{\prime} 23^{\prime \prime}-110^{\circ} 22^{\prime} 54^{\prime \prime}$ E (Figure 1), the total area is $126.8 \mathrm{~km}^{2}$, and the altitude is 1057.5-1334.1 m. This area is located at the junction of Yulin City in Shaanxi Province and Ordos City in the Inner Mongolia Autonomous Region. The ecological environment is fragile; the land is barren, and there is a serious degree of soil erosion. The region has a semiarid continental monsoon climate, with arid and cold winters, dry and hot summers, and a wide disparity in temperatures between day and night. The annual average temperature is $8.5^{\circ} \mathrm{C}$, and the annual extreme temperature is $28.1-38.9^{\circ} \mathrm{C}$. The annual average rainfall and evaporation are $441.2 \mathrm{~mm}$ and $2111.2 \mathrm{~mm}$, respectively, and the rainy season is mostly concentrated in the summer. The northwest winds prevail in late autumn, winter, and spring, and the southeast winds prevail in summer, with an average annual wind speed of $2.2 \mathrm{~m} / \mathrm{s}$. Most of the area is aeolian sand that has accumulated landforms, with sand dunes, sand ridges, and sand flats scattered about. The vegetation is sparse and primarily consists of Artemisia ordosica Krasch and Caragana korshinskii Kom [34]. There are many gullies in the east and west with strong cutting, and the bedrock on both sides of the gully is exposed. The USDA soil classification indicates that the soil type of Daliuta MA is sandy soil. Some primary agricultural products, such as maize (Zea mays L), foxtail millet (Setaria italica), and buckwheat (Fagopyrum esculentum Moench), are grown there.

\subsection{Sample Collection and Testing}

This research primarily focused on the investigation of soil $\mathrm{pH}, \mathrm{SOM}, \mathrm{AN}, \mathrm{AP}, \mathrm{AK}$, soil moisture, and soil salinity. The sampling time was October 2018. Factoring the uniformity and representativeness of the sample point distribution, a $1 \mathrm{~km} \times 1 \mathrm{~km}$ grid method was used to lay out the samples in the mining area for sampling, and GPS was used for accurate positioning. Based on the environmental characteristics of the Daliuta MA, a total 
of 143 samples (were selected to reflect the environmental quality of the soil in the MA. The specific distribution is shown in Figure 1. Within $3 \mathrm{~m}$ from the selected sample point, the surface soil $(0-20 \mathrm{~cm})$ of four subsample points was collected and mixed uniformly to form a sample, which consisted of approximately $1 \mathrm{~kg}$. After the soil samples were brought back to the laboratory for natural air drying and the removal of rocks, plant residues, leaves, and other debris, they were ground, passed through a 120-mesh sieve, marked, and tested.

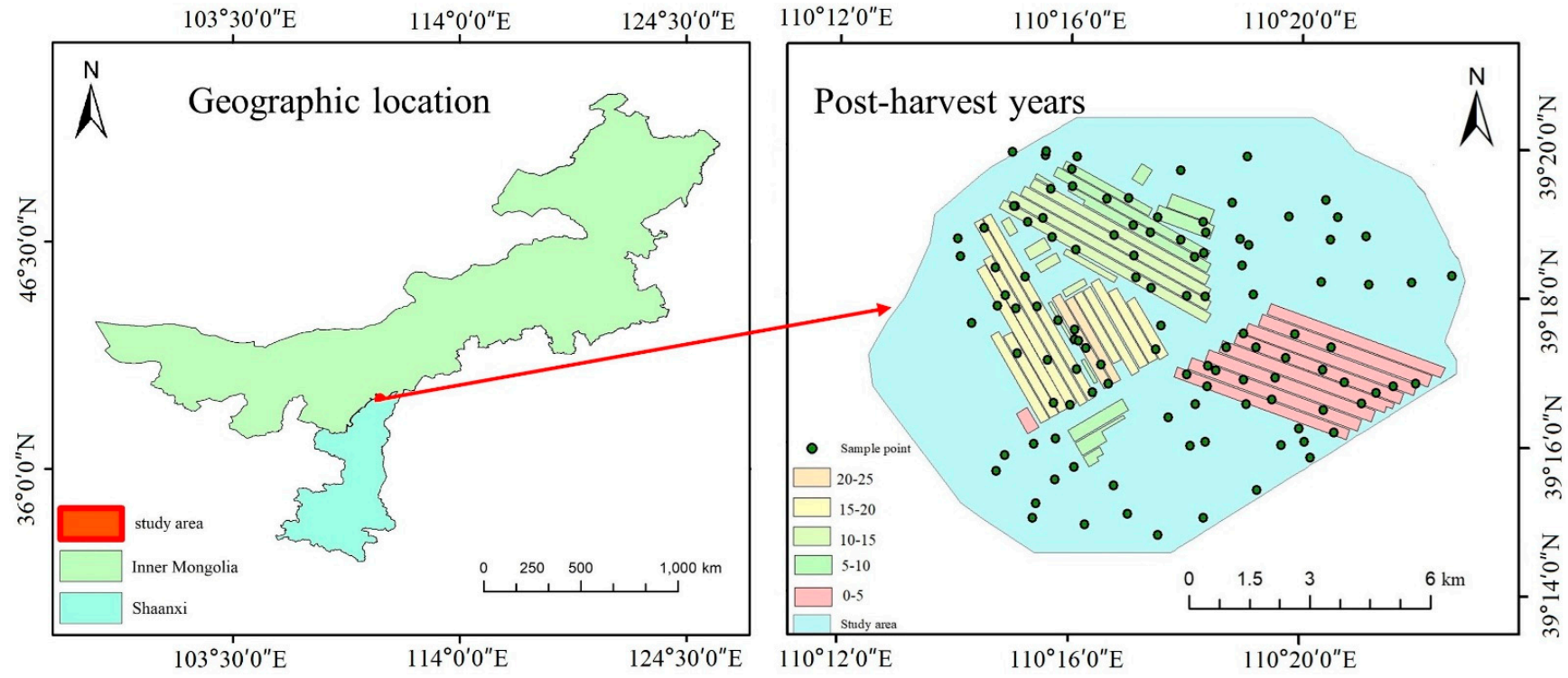

Figure 1. Distribution map of study area and sample points.

The soil salinity was measured by the conductivity method, and the soil water content was measured by the drying method. The $\mathrm{pH}, \mathrm{SOM}, \mathrm{AN}, \mathrm{AP}$, and AK were determined by the electrode potential [35], potassium chromate-external heating [36], alkaline solution-diffusion [37], molybdenum antimony anti-colorimetric [38], and ammonium acetate immersion flame luminosity methods [39], respectively.

\subsection{Data Processing Methods}

(1) Statistical methods

The data used the sample mean \pm three times the SD to identify the outliers. The data outside of this interval were identified as outliers, and the maximum and minimum values of the normal data were used instead. SPSS 26.0 (IBM, Inc., Armonk, NY, USA) was used to perform descriptive statistics, and the Kolmogorov-Smirnov (K-S) test on the 143 sample points. The K-S test is an empirical distribution function test that can assess whether the sample data follow a normal distribution [40]. Each nutrient was classified based on the nutrient classification standard of the second national soil survey. The function must meet the normal distribution during the semivariance function fitting, and then the $\mathrm{K}-\mathrm{S}$ test is performed on all indicators, and the data that do not conform to the normal distribution are used after normal conversion. The coefficient of variation is an indicator that reflects the degree of variation of soil nutrients. Based on the classification standard of the coefficient of variation [41], when the coefficient of variation $\leq 10 \%$, the sample was considered weakly variable; the coefficient of variation was considered medium variable when the value was between $10 \%$ and $100 \%$, and when the coefficient of variation $\geq 100 \%$, it was considered strongly variable. Based on the GIS spatial distribution map of soil nutrients, 500 sample points were randomly generated and processed by Origin2018 software (OriginLab, Northampton, MA, USA) to explore the effects of topographic factors, mining years, and soil erosion on the spatial distribution of soil nutrients.

(2) Spatial heterogeneity analysis methods of soil physical and chemical factors 
The semivariance function is the key function used to study the spatial variability of soil in geostatistics. It was fitted with GS+9.0 software, and the best theoretical model was selected as the variable whose residual was the closest to 0 and whose coefficient of determination was the closest to 1 . The nugget value $(\mathrm{C} 0)$ reflects the spatial variation caused by random factors. The sill value $(\mathrm{C} 0+\mathrm{C})$ reflected the spatial variation caused by structural factors, such as the soil parent material, topography, and random factors, such as fertilization and coal mining disturbance. The ratio of nugget value to sill value was an important indicator that reflected the degree of spatial variability of regionalized variables, and it was used to reflect the structural and random factors among the influencing factors of spatial variability who are dominant $[42,43]$. When the ratio was $<0.25$, the variables strongly spatially correlated. When $0.25 \leq$ nugget ratio was $\leq 0.75$, the variables moderately spatially autocorrelated. When the ratio was $>0.75$, they weakly spatially autocorrelated [44].

(3) Spatial interpolation methods of soil physical and chemical factors

The soil in the Daliuta MA is affected by the parent material, climate, topography, and mining activities during the process of soil formation, and the spatial distribution of soil nutrients presents a characteristic significant trend. Taking the east direction as the $\mathrm{X}$ axis, the north direction as the $\mathrm{Y}$ axis, and the measured values of each nutrient as the $\mathrm{Z}$ axis, the trend effect map was drawn in the Geostatistical Analyst of ArcGIS 10.2 (ESRI, Redlands, CA, USA). Since the conventional statistics of soil nutrient indicators can only represent the nutrient content of the selected sample points, it is impossible to analyze the local change characteristics to some extent. Kriging interpolation is a method of unbiased optimal estimation of unsampled areas using original data and semivariance function after trend effect analysis [45]. We could use the Geostatistical Analyst of ArcGIS 10.2 to perform Ordinary Kriging Interpolation on the soil nutrients to draw a map of the spatial distribution of soil nutrients.

(4) Extraction of terrain factors and soil erosion information

The soil erosion information was extracted and calculated using the RUSLE model in ArcGIS 10.2. Five topographic factors, including the slope (SLO), aspect (ASP), elevation (ELE), relief amplitude (RA), and topographic wetness index (TWI), were extracted based on the DEM data using the Spatial Analysis Tools of ArcGIS 10.2 (Supplementary Figure S1). The elevation data were downloaded from the geospatial data cloud website, and the map of the study area was obtained after a mask extraction. The SLO and ASP were obtained using the three-dimensional (3-D) analysis module; RA is the difference between the highest point and the lowest point in a specific area, which was obtained through the Focal Statistics module in the Spatial Analysis Tools. The extraction of TWI was first based on the Surface Toolbox to calculate the slope, based on the Hydrology Toolbox, to calculate the water flow direction, and confluence accumulation among others. It was calculated based on the TWI $=\ln$ [concentration per unit area/Tan (slope)].

To extract the soil erosion information, the revised universal soil loss equation RUSLE model [46] was used, and the formula was as follows:

$$
\mathrm{A}=\mathrm{RKLSCP}
$$

Among them, A was the predicted amount of soil erosion, which primarily refers to the average annual soil loss caused by rainfall and the runoff caused by rainfall and runoff on the slope surface rills or erosion between rills, $\mathrm{t} /\left(\mathrm{hm}^{2} \cdot \mathrm{a}\right)$. $\mathrm{R}$ was the rainfall erosivity factor, obtained from rainfall data, $\mathrm{MJ} \cdot \mathrm{mm} /\left(\mathrm{hm}^{2} \cdot \mathrm{h} \cdot \mathrm{a}\right)$. K was the soil erodibility factor, obtained from the soil data, $\mathrm{t} \cdot \mathrm{hm}^{2} \cdot \mathrm{h} /\left(\mathrm{hm}^{2} \cdot \mathrm{MJ} \cdot \mathrm{mm}\right)$. L and $\mathrm{S}$ were the slope lengths and factors, respectively, which represent the ratio of the amount of soil loss on a given slope length and slope to the amount of soil loss on a typical slope in a standard plot under the same conditions, extracted from DEM data and dimensionless. C and P were vegetation coverage and management factors and water and soil conservation measures factors, respectively. The former refers to the ratio of the amount of soil loss in a certain area under a certain crop or vegetation coverage to the amount of soil loss under continuous 
fallow conditions after cultivation in the area. It was dimensionless. The latter is the ratio of the amount of soil loss by taking water and soil conservation measures to the amount of soil loss by farming along the slope, which was obtained from remote sensing data and land use type maps, and it was dimensionless. By combining the SL190-2007 "Soil Erosion Classification and Grading Standard", we can classify soil erosion, which is divided into six grades of micro, mild, moderate, high, strong, and severe erosion [33].

\section{Results}

\subsection{Descriptive Statistics of Soil Nutrients}

The descriptive statistical results of soil nutrients in the study area are shown in Table 1. The $\mathrm{pH}$ value of soil in the Daliuta MA ranged from 6.86 to 8.95, which is slightly acidic to slightly alkaline. As shown by the second national soil survey tentative specifications in Chinese [47], the mean of SOM, AN, AP, and AK were $0.89 \%, 12.97 \mathrm{mg} / \mathrm{kg}, 2.34 \mathrm{mg} / \mathrm{kg}$, and $64.53 \mathrm{mg} / \mathrm{kg}$, which belong to grade five (very lacking), grade six (extremely lacking), and grade six (extremely lacking), and level four (medium), respectively. The average values of soil moisture and soil salinity were $0.74 \%$ and $0.55 \mathrm{~g} / \mathrm{kg}$, respectively, which was owing to the environment of drought and normal salinity. In terms of CV (coefficient of variation), the $\mathrm{pH}$ was $5.32 \%$ and weekly variable; the $\mathrm{SOM}, \mathrm{AN}, \mathrm{AP}, \mathrm{AK}$, and soil salinity were medium variability in the range of $10 \%$ to $100 \%$; soil moisture that exceeded $100 \%$ was strongly variable. Judging from the skewness and kurtosis data in the table, it has obvious characteristics of skewness. Under the 5\% single-sample K-S test, the original data were not normally distributed and needed to be normally transformed. The $\mathrm{pH}, \mathrm{SOM}$, and AK satisfied the logarithmic transformation of normal distribution. AN and AP conformed to a normal distribution after the square root transformation. Soil moisture and salinity were normally distributed after the Box-Cox transformation.

Table 1. Descriptive statistical characteristics of soil nutrient indicators.

\begin{tabular}{ccccccccc}
\hline Indicators & Min & Max & Mean & SD & CV (\%) & Skewness & Kurtosis & K-S Test \\
\hline pH & 6.86 & 8.95 & 8.27 & 0.44 & 5.32 & -1.07 & 0.83 & 0.053 \\
SOM $(\%)$ & 0.08 & 3.52 & 0.89 & 0.74 & 83.15 & 1.63 & 2.52 & 0.2 \\
AN $(\mathrm{mg} / \mathrm{kg})$ & 0.00 & 55.83 & 12.97 & 10.35 & 79.80 & 1.66 & 3.70 & 0.081 \\
$\mathrm{AP}(\mathrm{mg} / \mathrm{kg})$ & 0.00 & 10.06 & 2.34 & 2.00 & 85.47 & 1.98 & 5.00 & 0.2 \\
$\mathrm{AK}(\mathrm{mg} / \mathrm{kg})$ & 19.02 & 199.35 & 64.53 & 42.02 & 65.12 & 1.54 & 1.87 & 0.2 \\
Moisture $(\%)$ & 0.07 & 4.18 & 0.74 & 0.84 & 113.51 & 2.49 & 6.29 & 0.06 \\
EC (ms/cm) & 0.82 & 3.05 & 1.53 & 1.23 & 65.45 & 1.08 & 0.63 & 0.2 \\
\hline
\end{tabular}

The K-S test in the table is the result of normal conversion of the original data.

\subsection{Spatial Variability Characteristics}

The fitting results of the semivariance function and related parameters are shown in Table 2. The best semivariance fitting model for the SOM, AK, AP, and soil moisture was an exponential model, and the optimal model for $\mathrm{pH}, \mathrm{AN}$, and soil salinity was a spherical model $>0$, indicating that there are random factors, such as sampling process and measurement error, and natural factors, such as topography and parent material, in the research area, that cause spatial heterogeneity. The nugget effects of SOM, pH, and soil salinity were all $<0.75$, with moderate spatial autocorrelation, indicating that its spatial variability was caused by both random and natural factors. The nugget effects of AN, AK, AP, and soil moisture were between 0.795 and 0.932 , demonstrating weak spatial autocorrelation, and the influence of random factors is dominant. The soil nutrients in the Daliuta MA are affected by human factors, such as the degree of mining, ecological restoration, land reclamation, and terrain and soil parent materials, which increase structural differences, resulting in different nutrient indicators in different locations that show different degrees of spatial autocorrelation. The range of variation of the seven indicators was not large, indicating that the spatial distribution was weak. Therefore, the variation within a small range could not be ignored. 
Table 2. Soil nutrient semivariance function and related parameters.

\begin{tabular}{cccccccc}
\hline Indicators & Model & $\mathbf{C}_{\mathbf{0}}$ & $\mathbf{C}_{\mathbf{0}}+\mathbf{C}$ & $\mathbf{C}_{\mathbf{0}} /\left(\mathbf{C}_{\mathbf{0}}+\mathbf{C}\right)$ & $\mathbf{R S S}$ & $\mathbf{R}^{\mathbf{2}}$ & $\begin{array}{c}\text { Range } \\
(\mathbf{k m})\end{array}$ \\
\hline SOM & exponential & 0.319 & 0.639 & 0.501 & 0.035 & 0.458 & 0.090 \\
pH & spherical & 0.006 & 0.014 & 0.558 & $2.468 \times 10^{-6}$ & 0.939 & 0.145 \\
AN & spherical & 0.112 & 1.651 & 0.932 & 0.136 & 0.236 & 0.015 \\
AK & exponential & 0.086 & 0.419 & 0.795 & $1.042 \times 10^{-3}$ & 0.816 & 1.140 \\
AP & exponential & 0.050 & 0.307 & 0.839 & 0.018 & 0.652 & 0.003 \\
EC & spherical & 0.070 & 0.014 & 0.504 & $4.517 \times 10^{-4}$ & 0.897 & 0.069 \\
Moisture & exponential & 0.075 & 0.518 & 0.855 & 0.017 & 0.124 & 0.015 \\
\hline
\end{tabular}

Depending on the location of the sample, the sample points located on the working surface are the sample points in the mining area, and the others are nonmining samples. $\mathrm{AK}, \mathrm{AN}$, and $\mathrm{AP}$ in the nonmining area of the Daliuta mining area showed an inverted " $U$ " shape in the east-west projection line and south-north direction, all of which are second-order trend effects, as shown in Figure 2. The $\mathrm{pH}$ and soil salinity showed a " $\mathrm{U}$ " shape in the east-west and south-north directions, which were second-order trend effects. The projection line of SOM in the east-west direction was a straight line, which gradually increased from west to east, and it was also a straight line in the south-north direction, decreasing from north to south, and the trend effect was first-order. The projection line of AP in the east-west direction was slightly convex, and it was in the shape of a " $U$ " in the north-south direction. The trend effect was second-order. The soil moisture in the east-west direction was in the inverted " $U$ " shape, and the water in the south-north direction was a slight " $U$ ". The shape was a second-order trend effect. Under the influence of coal mining, the projection of AK in MA in the east-west direction was an inverted " $U$ " shape, which was a second-order trend effect, and it was a straight line in the south-north direction. The trend effect was a first-order. The AN and soil salinity were in an inverted " $U$ " shape in the east-west direction and a " $U$ " shape in the south-north direction, and the trend effect was second-order. The projection line of AP in the east-west direction was a straight line, which was a first-order trend effect, and the south-north direction was in a "U" shape, which was a second-order effect. The $\mathrm{pH}$ was shaped like a " $\mathrm{U}$ " in the east-west direction, which was a second-order trend effect, and it was a straight line in the south-north direction, which increased from the north to south, and the trend effect was the first-order. The projection line of SOM in the east-west and south-north directions was a curve, which was a secondorder trend effect, and the soil moisture in the east-west and south-north directions was an inverted U-shaped curve, indicating that the trend effect was second-order. This shows that the spatial autocorrelation ranges of the soil nutrient indices are quite different, and the degree of spatial heterogeneity dependence on the scale is different. The sampling interval should be adjusted according to the characteristics of each nutrient index.

\subsection{Spatial Distribution}

Based on the model described above (Table 2), the spatial distribution map of soil nutrients was drawn in ArcGIS (Figure 3). The interpolation results enabled the observation that the AP did not show a particular spatial distribution law (Figure 3a). The contents of AK and AN were high, and the soil with low content was located in the northern part of the mining area (Figure $3 b, c)$. The soil in the study area ranged from weakly acidic to weakly alkaline, and the $\mathrm{pH}$ in the southwest was normally high (Figure 3d). The SOM was primarily distributed in the southwest of the mining area (Figure 3e). With the exception of the southeast region, the other regions had relatively little water (Figure 3f). The areas with higher salt content in the mining area were the southern and northern areas (Figure 3g). This could be owing to the degraded grassland in the mining area, lack of vegetation, and the accumulation of litter. Simultaneously, it is also related to the terrain of the mining area, the physical and chemical properties of the soil, and the coal mining history. 

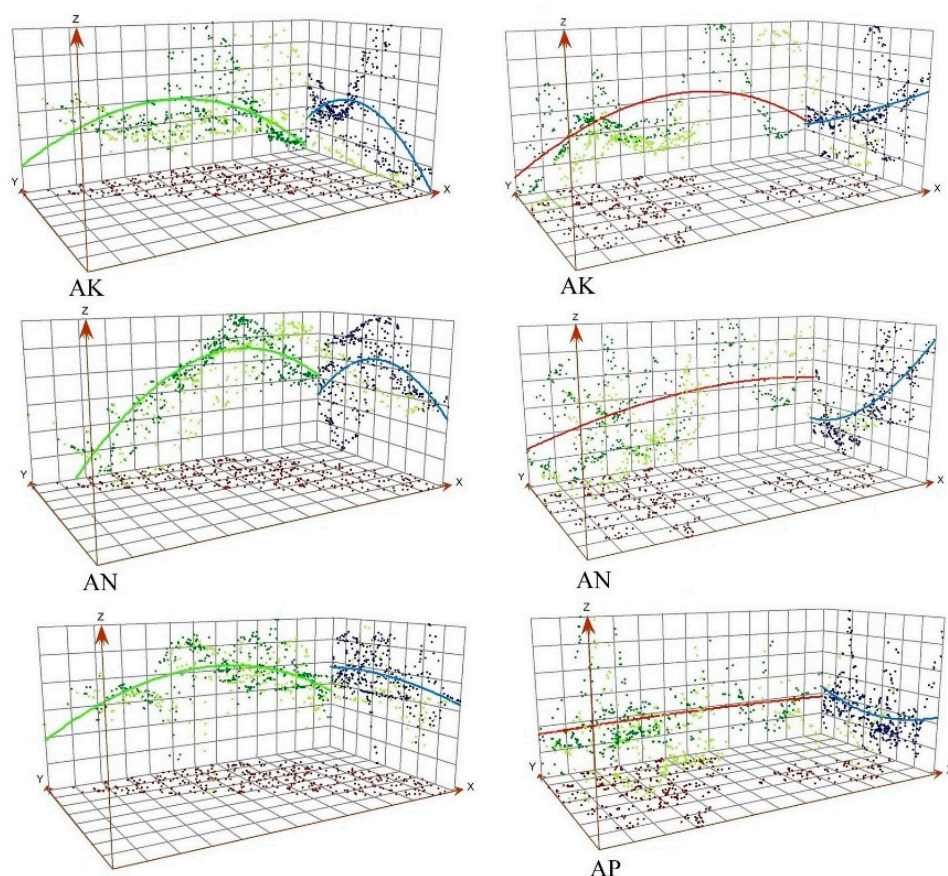

AN
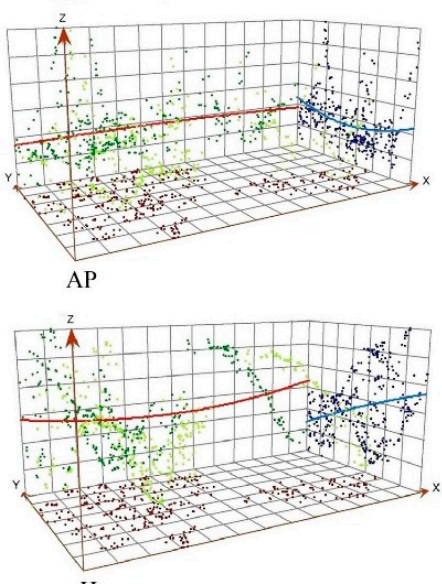

$\mathrm{pH}$
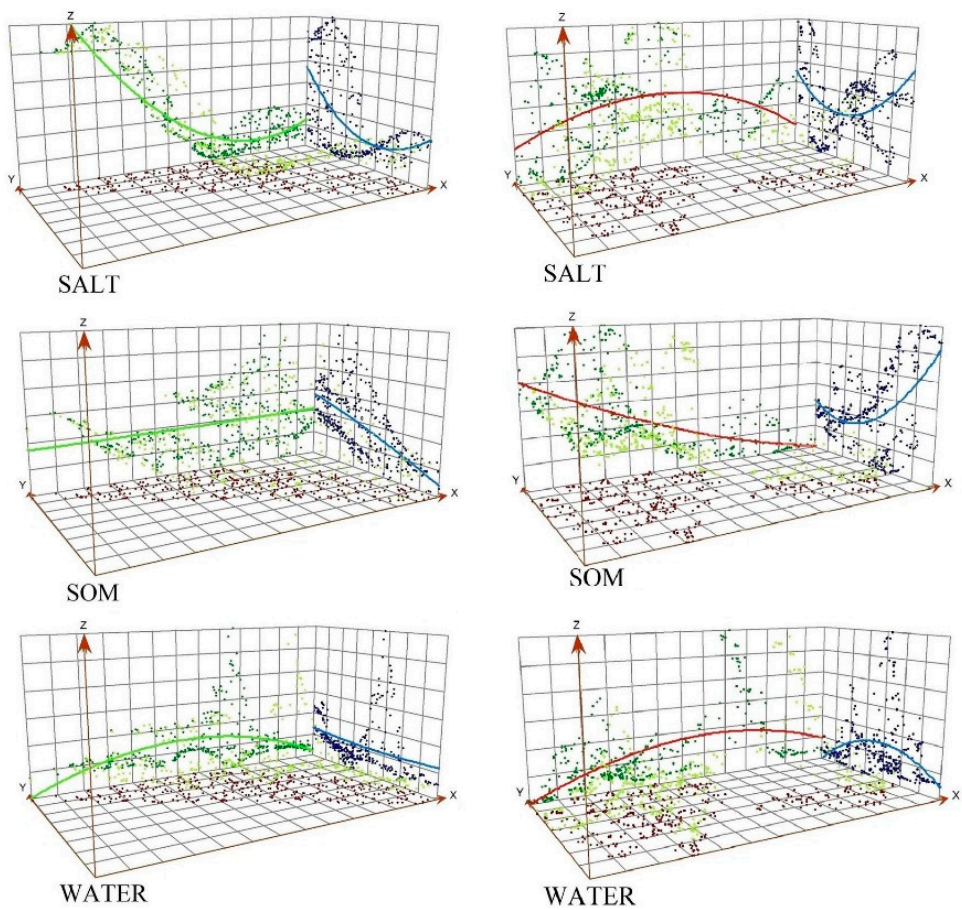

(a)Non-mining area trend effect

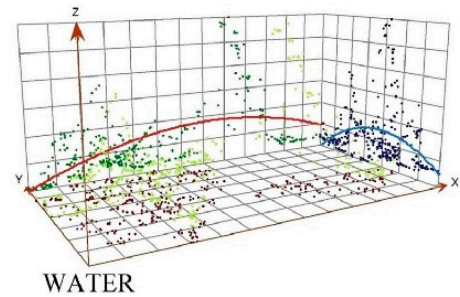

(b) Mining area trend effect

Figure 2. Trend effect maps of soil nutrient indicators ((a) is nonmining area, (b) is mining area). 

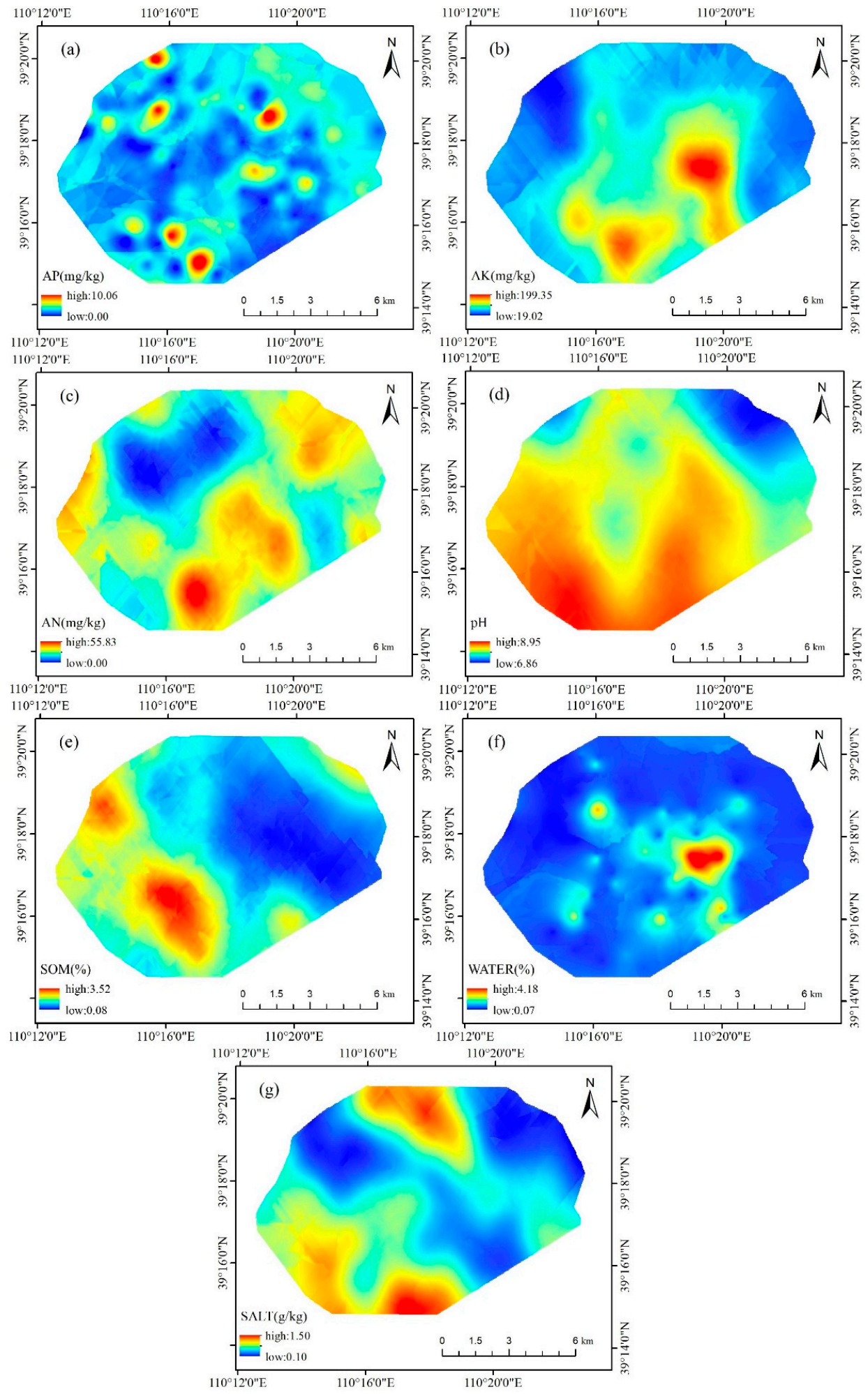

Figure 3. Spatial distribution map of soil nutrient indicators: (a) available phosphorus; (b) available potassium; (c) available nitrogen; (d) $\mathrm{pH}$; (e) soil organic matter; (f) water; (g) salt.

\section{Discussion}

The results of the spatial variability characteristics show that the spatial variability of SOM, $\mathrm{pH}$, and soil salinity is caused by both random and natural factors, while the influence of random factors is dominant for $\mathrm{AN}, \mathrm{AK}, \mathrm{AP}$, and soil moisture. The soil nutrients in the Daliuta MA are affected by human factors, such as the extent of mining, 
ecological restoration, and land reclamation, as well as by the terrain and soil parental material. Different nutrient indicators at varying locations show different degrees of spatial autocorrelation. Therefore, this paper selected five topographic factors as natural factors and then mining time and soil erosion as random factors and discussed their effects on the spatial variability of soil nutrients.

\subsection{Correlation Analyses}

Five hundred sample points were randomly generated in the ArcGIS software, including the statistics of terrain factors and soil nutrient index content. A significance test and correlation analysis on them are shown in Figure 4. Among them, the SOM, AN, AK, AP, SALT, and WATER are the soil organic matter, available nitrogen, available potassium, available phosphorus, soil salinity, and soil moisture, respectively. RA, TWI, ELE, SLO, ASP, and EROSION are the relief amplitude, topographic wetness index, elevation, slope, aspect, and soil erosion grade, respectively. It can be observed in Figure 4 that there is no significant relationship between the RA and content of each soil nutrient, indicating that it has little effect on the spatial variability of soil nutrients. The soil organic matter is affected by the combined effects of aspect, elevation, and topographic wetness index. The content of soil moisture is primarily affected by the topographic wetness index and elevation. The available potassium is greatly affected by slope and elevation; aspect and elevation are the main factors that restrict $\mathrm{pH}$. The contents of salinity and available phosphorus were affected by this aspect.

\section{Correlation Heatmap}

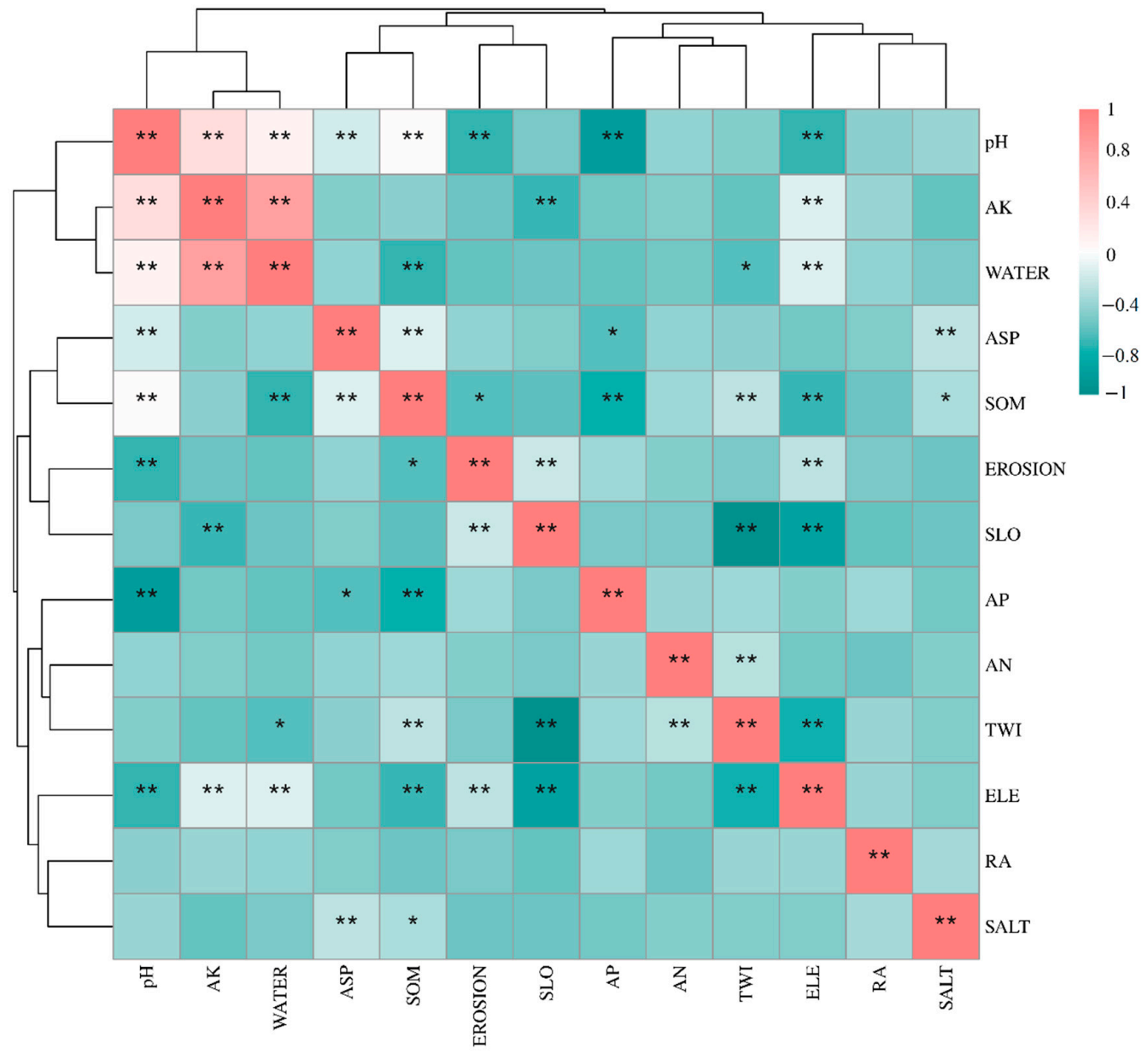

Figure 4. The correlation heat map of topographic factors, soil erosion grade and soil nutrients. * level of significance $(p<0.05) ;{ }^{* *}$ level of significance $(p<0.01)$. 


\subsection{The Influence of Topographical Factors on Soil Nutrients}

To further understand the influence of aspect, slope, elevation, and topographic wetness index on the spatial distribution of soil nutrients, this study divided the aspects into planes, shades, and half-shady slopes, half-sunny slopes, and sunny slopes based on $-1^{\circ}, 0-45^{\circ}$ and $315-360^{\circ}, 45-90^{\circ}$ and $270-315^{\circ}, 90-135^{\circ}$ and $225-270^{\circ}$, and $135-225^{\circ}$ [48]. The slope, topographic wetness index, and elevation were divided into five groups based on the equidistant method; we performed a statistical analysis, and the results are shown in Figures 5 and 6.
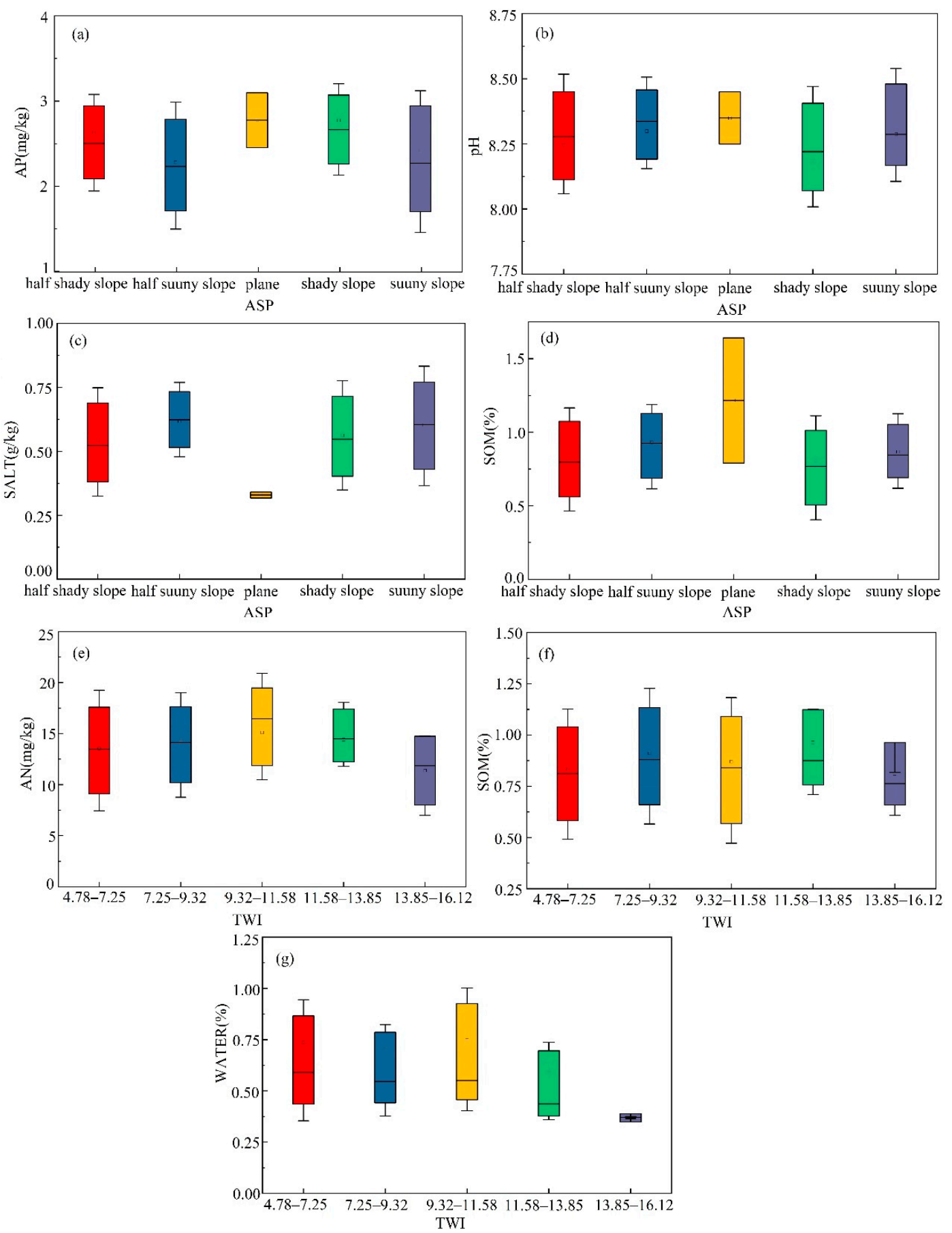

Figure 5. Statistics of AP (a), $\mathrm{pH}(\mathbf{b})$, salinity (c), and SOM (d) content under different ASP and statistics of AN (e), SOM (f), and soil moisture (g) content under different TWI. Elevation. 

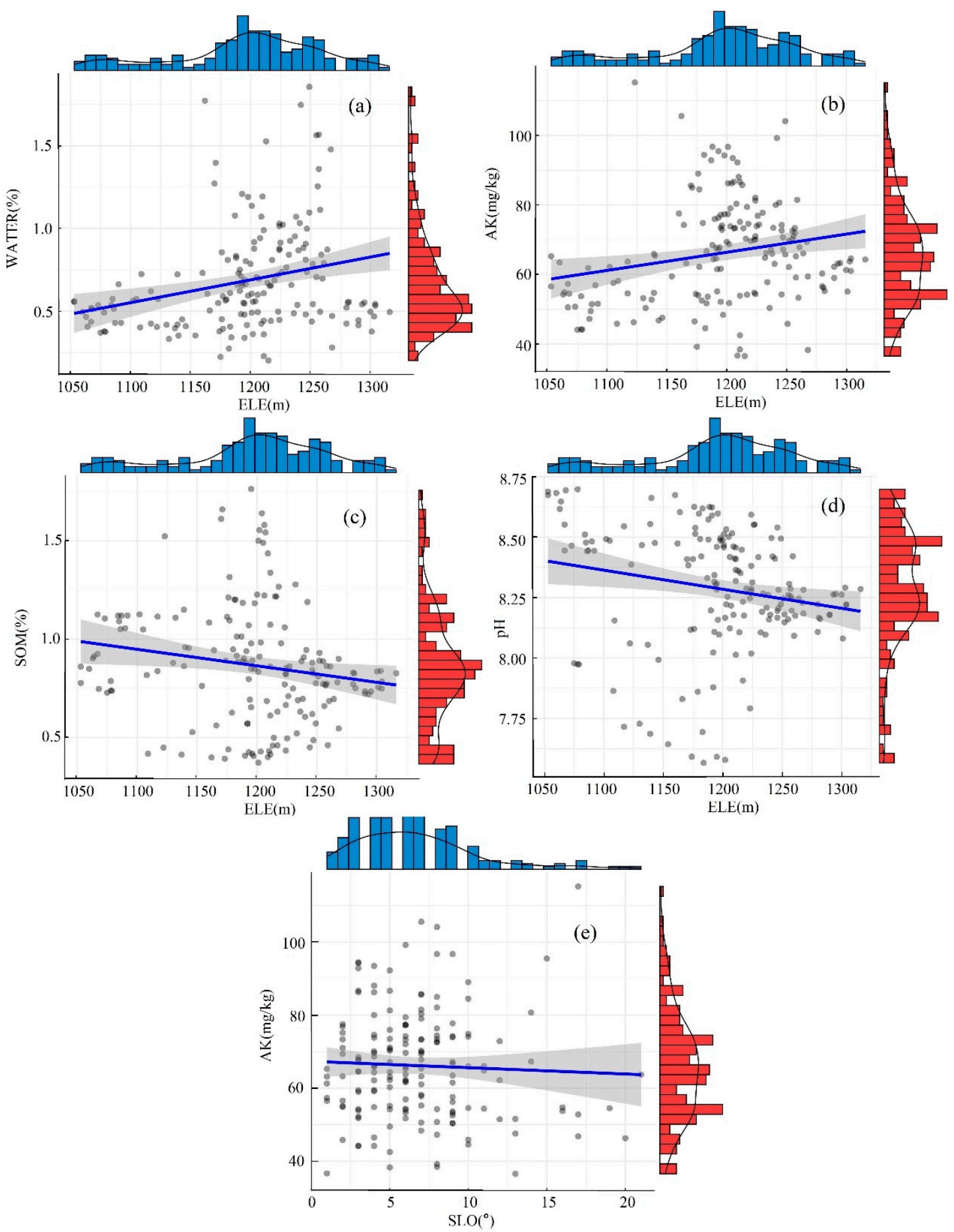

Figure 6. Statistics of soil moisture (a), AK (b), SOM (c), and pH (d) content under different ELE and statistics of AK content under different SLO (e).

\section{(1) Slope aspect}

As an important topographic factor, the slope aspect primarily affects the spatial distribution of soil nutrients by affecting the light intensity and rain conditions received by the soil, as observed in Figure 5a-d. This indicated that the soil salt content on the sunny slope was the highest, which could be caused by the accumulation of soil salt on the surface of the hillside caused by coal mining. The $\mathrm{pH}$ value is primarily higher on the plane, which may be caused by more frequent human activities on the plane. The content of organic matter is expressed as the sunny slope, half-sunny slope $>$ shady slope, and half shady 
slope. This could be because the sunny slope has strong sunlight and more substantial evaporation of water, which deleteriously affects the activities of microorganisms, while the shady and half-shady slopes receive moderate light, suitable temperature, and are prone to microbial activities. The sunny and half-sunny slopes decompose and transform more slowly, which is more conducive to the accumulation of SOM [49]. The average level of AP on the shady slope is significantly higher than that on the sunny slope, which could be related to the distribution of plants because the phosphorus in the soil primarily originates from the parent material of the soil.

(2) Topographic wetness index

The TWI can reflect the spatial distribution of surface water systems and affect the spatial distribution of soil nutrients to some extent. They were divided into five groups based on the equal interval method for statistics (Figure 5e-g). The results show that, with the increase in the TWI, the SOM and AP show a trend of first increasing and then decreasing. The reason could be that when the TWI is moderate, the rate of decomposition of microorganisms increases, and the rate of decomposition and oxidation of the organic matter and nitrogen accelerates, which reduces the content of SOM and AN. The average level of soil moisture content also tends to decrease with the TWI. The main reason is that the soil moisture will be affected by various factors, such as land use mode, aspect, slope, and slope position when it is close to the surface.

\section{(3) Elevation}

Elevation affects the temperature, light, and moisture that the soil receives, thereby causing changes in the spatial distribution of soil nutrients. As observed in Figure $6 a-d$, the contents of water and AK tend to increase with the increase in elevation. This could be owing to the increase in elevation, the higher soil moisture content, and the lower the decomposition efficiency of the material, resulting in an increase in the soil available potassium content. The content of organic matter and $\mathrm{pH}$ decreases with the increase of elevation, which is inconsistent with the results of other studies [50]. It could be caused by the natural environment in the study area. The study area is a windy and sandy area, mostly degraded grassland, that lacks vegetation and does not accumulate litter.

\section{(4) Slope}

The soil water holding capacity and surface particle migration differed with different slopes, and this will indirectly affect the status of soil fertility. Based on the DEM data of the study area, the slope was extracted, and the AP content in different slope ranges was counted (Figure 6e). The content of AP was found to be concentrated at approximately $60 \mathrm{mg} / \mathrm{kg}$, and the slope is primarily distributed in the range of $0-10^{\circ}$. The content of AK tends to decrease as the slope increases owing to the increase in slope. The soil is affected by rainfall or surface runoff, and the effect of leaching is strengthened [51]. The available potassium is lost extremely easily, which causes the loss of soil that reduces the content of available potassium.

\subsection{The Impact of Soil Erosion on Soil Nutrients}

An exploration of the correlation analysis between the level of soil erosion and various soil nutrients showed that the soil erosion grade significantly positively correlates with elevation and slope $(p<0.01)$. In contrast, it significantly negatively correlated with the $\mathrm{pH}$ $(p<0.01)$ and SOM $(p<0.05)$. The classification of soil erosion and the $\mathrm{pH}$ and SOM in each range were counted separately (Figure 7). The SOM and $\mathrm{pH}$ decreased with the increase in level of soil erosion, possibly because the Daliuta MA is located at the intersection of the southern margin of the Mu Us Desert, the fifth largest desert in China, and the Loess Plateau. It belongs to a windy area that accumulates sand, with less rainfall and sparse vegetation, which easily causes soil erosion. Soil erosion changes the original rock and soil structure and affects the growth of vegetation. As a result, the vegetation coverage has 
decreased, erosion by wind has increased, and soil erosion has been severe, removing more base ions and organic matter [52].

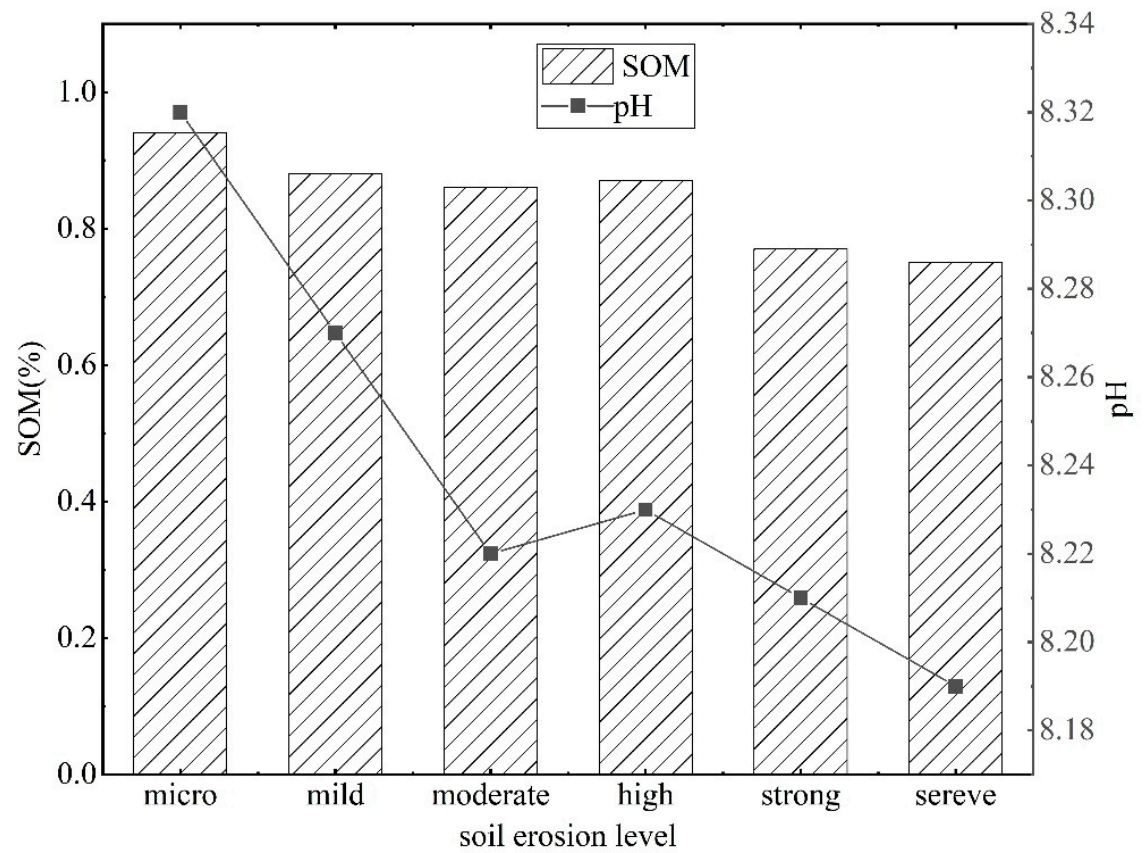

Figure 7. SOM and $\mathrm{pH}$ values of different soil erosion levels.

\subsection{The Impact of Mining Years on Soil Nutrients}

The spatial variability characteristics of soil nutrients indicate that the soil parent material, human activities, and coal mining disturbances have some relationship with the spatial distribution of soil nutrients. Among them, the impact of coal mining disturbances can be quantified by the characteristics of soil nutrients in working faces with different mining years. Therefore, this paper divides the Daliuta MA working faces according to the mining time of the working faces, which are divided into $0-5$ years, 5-10 years, $10-15$ years, 15-20 years, and 20-25 years after mining [53].

Group statistics were performed, and the results are shown in Figure 8. The AK, AN, $\mathrm{AP}, \mathrm{pH}$, salinity, and water content in different postharvest years tend to first decrease and then increase. This shows that the soil ecosystem has some ability to recover under the disturbance of a coal mining collapse, but the restoration of soil nutrients in the collapsed area is still a long-term process. For the soil system in the mining area, once the degree of disturbance exceeds the threshold of the key influencing factors, the system has difficulty recovering [54]. The loss of soil nutrients results in poor vegetation, which will be degraded. In this paper, the soil nutrient content began to increase approximately 10-15 years after harvesting, and the soil environmental conditions improved. However, the loss of soil nutrients is still severe in areas with severe soil damage or intensive human activities. This improvement is regional, and these areas are the key ones that require attention in the future to improve soil quality. 

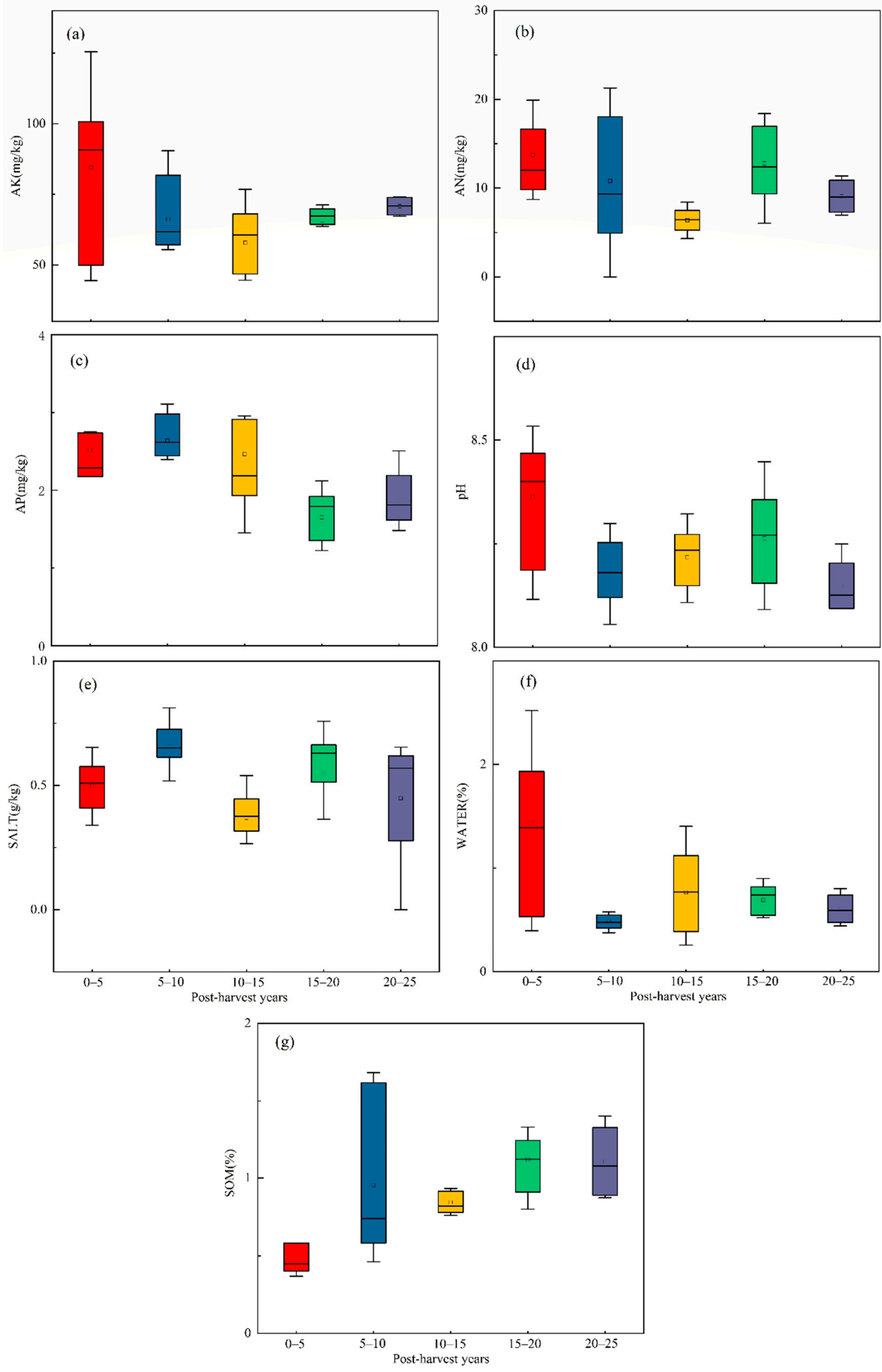

Figure 8. Comparison of $\mathrm{AK}(\mathbf{a}), \operatorname{AN}(\mathbf{b}), \operatorname{AP}(\mathbf{c}), \mathrm{pH}(\mathbf{d}), \operatorname{SALT}(\mathbf{e})$, WATER (f), and SOM (g) in different mining years. 


\section{Conclusions}

In this paper, through descriptive statistics, spatial variability characteristics, trend effects, and the spatial distribution analysis of soil nutrients in the Daliuta MA, the main factors that affect the spatial distribution of soil nutrients are explored. The main conclusions are as follows, and the hope of this study is that they will provide a reference for soil guided restoration in mining areas:

(1) The soil in the Daliuta MA is slightly acidic to slightly alkaline and is a component of an arid and normal salinity environment. The contents of SOM, AN, and AP are highly limited, and the content of $\mathrm{AK}$ is moderate. The $\mathrm{pH}$ varies weakly, and the organic matter, $\mathrm{AN}, \mathrm{AP}, \mathrm{AK}$, and soil salinity are medium variable, and the soil moisture is strongly variable.

(2) The best semivariance fitting model for the SOM, AK, AP, and soil moisture is an exponential model, and the best model for $\mathrm{pH}, \mathrm{AN}$, and soil salinity is a spherical model. The nugget effect of the $\mathrm{SOM}, \mathrm{pH}$, and soil salinity moderately spatially auto-correlate, and the spatial variability is caused by both random and natural factors. The AN, AK, $\mathrm{AP}$, and soil moisture weakly spatially auto-correlate, and the influence of random factors dominates. The range of variation of the seven indicators is not large; the uniformity of spatial distribution is weak, and the variation within a small range cannot be ignored.

(3) Each nutrient index has a particular spatial trend effect. The contents of AK and AN are higher in the southeast of the MA, and the soil with low content is located in the northern part of the MA. This could be because the MA is mostly degraded grassland and does not accumulate vegetation or litter. The areas with higher salt content are the southern and northern areas of the MA, and the SOM is primarily distributed southwest of the MA. With the exception of the central and southern parts, the water content in other regions is relatively low, and there is no apparent trend for the spatial distribution of AP.

(4) The SOM is affected by the combined effects of ASP, ELE, TWI, and soil erosion. The soil moisture content is primarily affected by TWI and ELE. The AK is substantially affected by SLO and ELE. ASP, ELE, and soil erosion are the main factors that restrict the $\mathrm{pH}$. The salinity and AP are affected by the ASP. The contents of AK, AN, AP, pH, salinity, and water in different postharvest years tend to first decrease and then increase. The soil has some ability to recover under the disturbance of a coal mine collapse, but the restoration of soil nutrients in the collapsed area remains a long-term process.

Supplementary Materials: The following supporting information can be downloaded at: https: //www.mdpi.com/article/10.3390/su14052793/s1, Figure S1: The results of extracting topographic factors and soil erosion: (a) aspect; (b) elevation; (c) relief amplitude; (d) slope; (e) topographic wetness index; (f) erosion.

Author Contributions: Conceptualization, L.L., Y.L. and X.C.; Formal analysis, L.L.; Funding acquisition, Y.L., X.C. and S.L.; Investigation, L.L. and J.G.; Methodology, L.L. and Y.L.; Resources, L.L. and J.G.; Visualization, X.Z.; Writing—original draft, L.L.; Writing—review and editing, Y.L., X.L. and Y.G. All authors have read and agreed to the published version of the manuscript.

Funding: This work was supported by the Open Fund of State Key Laboratory of Water Resource Protection and Utilization in Coal Mining (WPUKFJJ2019-16), University-level key projects of Anhui University of Science and Technology (xjzd2020-04), Natural Science Research Project of Anhui Higher Education Institution (KJ2021A0423), National Key Basic Research and Development Program (2013cb227904).

Institutional Review Board Statement: Not applicable.

Informed Consent Statement: Not applicable.

Data Availability Statement: Data are contained in the tables of the article.

Acknowledgments: The authors thank the Open Fund of State Key Laboratory of Water Resource Protection and Utilization in Coal Mining and Anhui University of Science and Technology for their strong support in data use and funding. The authors also thank the reviewers for their constructive suggestions on the modification and improvement of the manuscript. 
Conflicts of Interest: The authors declare no conflict of interest.

\section{References}

1. Bian, Z.F. A summary of researches on land reclamation in coal mining areas at home and abroad. China Land Sci. 2000, 14, 6-11. [CrossRef]

2. Ayoubi, S.; Mehnatkesh, A.; Jalalian, A.; Sahrawat, K.L.; Gheysari, M. Relationships between grain protein, Zn, Cu, Fe and Mn contents in wheat and soil and topographic attributes. Arch. Agron. Soil Sci. 2014, 60, 625-638. [CrossRef]

3. Khormali, F.; Ajami, M.; Ayoubi, S.; Srinivasarao, C.; Wani, S.P. Role of deforestation and hillslope position on soil quality attributes of loess-derived soils in Golestan province, Iran. Agric. Ecosyst. Environ. 2009, 134, 178-189. [CrossRef]

4. Ayoubi, S.P.; Khormali, F.; Sahrawat, K.L.; Rodrigues De Lima, A.C. Assessment of soil quality indicators related to land use change in a loessial soil using factor analysis in Golestan province, northern Iran. J. Agric. Sci. Technol. 2010, 13, 727-742.

5. Chuai, X.; Qi, X.; Zhang, X.; Li, J.; Yuan, Y.; Guo, X.; Huang, X.; Park, S.; Zhao, R.; Xie, X.; et al. Land degradation monitoring using terrestrial ecosystem carbon sinks/sources and their response to climate change in China. Land Degrad. Dev. 2018, 29, 3489-3502. [CrossRef]

6. Wang, J.; Wen, X.; Lyu, S.; Zhang, X.; Li, S.; Guo, Q. Vegetation recovery alters soil N status in subtropical karst plateau area: Evidence from natural abundance $\delta-15 \mathrm{~N}$ and $\delta-18 \mathrm{O}$. Plant Soil 2021, 460, 609-623. [CrossRef]

7. Raphael, L.J. Vegetation Land Cover/Use Dynamics and Their Effects in Mbulu and Karatu Districts in the North-Eastern Highlands of Tanzania. Int. J. Geospat. Environ. Res. 2018, 5, 5. Available online: https://dc.uwm.edu/ijger/vol5/iss1/5 (accessed on 25 February 2022).

8. Abdel-Kader, F.H. Assessment and monitoring of land degradation in the northwest coast region, Egypt using Earth observations data. Egypt. J. Remote Sens. Space Sci. 2019, 22, 165-173. [CrossRef]

9. Fathizad, H.; Ardakani, M.A.H.; Mehrjardi, R.T.; Sodaiezadeh, H. Evaluating desertification using remote sensing technique and object-oriented classification algorithm in the Iranian central desert. J. Afr. Earth Sci. 2018, 145, 115-130. [CrossRef]

10. Ahirwal, J.; Maiti, S.K.; Singh, A.K. Changes in ecosystem carbon pool and soil $\mathrm{CO}_{2}$ flux following post-mine reclamation in dry tropical environment, India. Sci. Total Environ. 2017, 583, 153-162. [CrossRef]

11. Sun, W.; Li, B.S. An approach to classification and assessment of desertification. Geogr. Res. 1999, 18, 225-230. [CrossRef]

12. Xie, H.; Zhang, Y.; Wu, Z.; Lv, T. A Bibliometric Analysis on Land Degradation: Current Status, Development, and Future Directions. Land 2020, 9, 28. [CrossRef]

13. Yang, C.; Li, Q.; Chen, J.; Wang, J.; Shi, T.; Hu, Z.; Ding, K.; Wang, G.; Wu, G. Spatiotemporal characteristics of land degradation in the Fuxian Lake Basin, China: Past and future. Land Degrad. Dev. 2020, 31, 2446-2460. [CrossRef]

14. Zhang, Y.Z.; Hu, Y.F.; Han, Y.Q.; Zhan, S. Spatial distributions and evolutions of global major ecological degradation regions and research hot spot regions. Acta Ecol. Sin. 2021, 41, 7599-7613. [CrossRef]

15. Ren, H.; Zhao, Y.; Xiao, W.; Hu, Z. A review of UAV monitoring in mining areas: Current status and future perspectives. Int. J. Coal Sci. Technol. 2019, 6, 320-333. [CrossRef]

16. Bungau, S.; Behl, T.; Aleya, L.; Bourgeade, P.; Aloui-Sossé, B.; Purza, A.L.; Abid, A.; Samuel, A.D. Expatiating the impact of anthropogenic aspects and climatic factors on long-term soil monitoring and management. Environ. Sci. Pollut. Res. 2021, 28, 30528-30550. [CrossRef]

17. Samuel, A.D.; Bungau, S.; Tit, D.M.; Melinte, C.E.; Purza, L.; Badea, G.E. Effects of long-term application of organic and mineral fertilizers on soil enzymes. Rev. Chim. 2018, 69, 2608-2612. [CrossRef]

18. Samuel, A.D.; Tit, D.M.; Melinte, C.E.; Iovan, C.; Purza, L.; Gitea, M.; Bungau, S. Enzymological and physicochemical evaluation of the effects of soil management practices. Rev. Chim. 2017, 68, 2243-2247. [CrossRef]

19. Dankoub, Z.; Ayoubi, S.; Khademi, H.; Lu, S.-G. Spatial distribution of magnetic properties and selected heavy metals in calcareous soils as affected by land use in the Isfahan region, Central Iran. Pedosphere 2012, 22, 33-47. [CrossRef]

20. Zolfaghari, Z.; Mosaddeghi, M.R.; Ayoubi, S. ANN-based pedotransfer and soil spatial prediction functions for predicting Atterberg consistency limits and indices from easily available properties at the watershed scale in western Iran. Soil Use Manag. 2015, 31, 142-154. [CrossRef]

21. Zolfaghari, Z.; Ayoubi, S.; Mosaddeghi, M.R. Spatial variability of some soil shrinkage indices in hilly calcareous region of western Iran. Soil Tillage Res. 2015, 150, 180-191. [CrossRef]

22. Azadmard, B.; Mosaddeghi, M.R.; Ayoubi, S.; Chavoshi, E.; Raoof, M. Spatial variability of near-saturated soil hydraulic properties in Moghan plain, North-Western Iran. Arab. J. Geosci. 2018, 11, 452. [CrossRef]

23. Zeraatpisheh, M.; Ayoubi, S.; Sulieman, M.; Rodrigo-Comino, J. Determining the spatial distribution of soil properties using the environmental covariates and multivariate statistical analysis: A case study in semi-arid regions of Iran. J. Arid Land 2019, 11, 551-566. [CrossRef]

24. Ajami, M.; Heidari, A.; Khormali, F.; Zeraatpisheh, M.; Gorji, M.; Ayoubi, S. Spatial variability of rainfed wheat production under the influence of topography and soil properties in loess-derived soils, northern Iran. Int. J. Plant Prod. 2020, 14, 597-608. [CrossRef]

25. Zeraatpisheh, M.; Ayoubi, S.; Mirbagheri, Z.; Mosaddeghi, M.R.; Xu, M. Spatial prediction of soil aggregate stability and soil organic carbon in aggregate fractions using machine learning algorithms and environmental variables. Geoderma Reg. 2021, 27, e00440. [CrossRef] 
26. Huggett, R.J. Soil chronosequences, soil development, and soil evolution: A critical review. Catena 1998, 32, 155-172. [CrossRef]

27. Zhang, Z.L.; Zuo, X.H.; Liu, F.; Shi, X.J. Spatial heterogeneity of soil readily available potassium and its influencing factors in Western Chongqing Hilly Area. Acta Pedol. Sin. 2020, 57, 307-315. [CrossRef]

28. Dai, W.; Li, Y.; Fu, W.; Jiang, P.; Zhao, K.; Li, Y.; Penttinen, P. Spatial variability of soil nutrients in forest areas: A case study from subtropical China. J. Plant Nutr. Soil Sci. 2018, 181, 827-835. [CrossRef]

29. Dai, W.; Zhao, K.; Fu, W.; Jiang, P.; Li, Y.; Zhang, C.; Gielen, G.; Gong, X.; Li, Y.; Wang, H.; et al. Spatial variation of organic carbon density in topsoils of a typical subtropical forest, southeastern China. Catena 2018, 167, 181-189. [CrossRef]

30. Razan Malla, S.S.D.K. Soil Fertility Mapping and Assessment of the Spatial Distribution of Sarlahi District, Nepal. Am. J. Agric. Sci. 2020, 7, 8-16. Available online: https:/ / www.researchgate.net/publication/33978125 (accessed on 25 February 2022).

31. Sharma, R.; Sood, K. Characterization of Spatial Variability of Soil Parameters in Apple Orchards of Himalayan Region Using Geostatistical Analysis. Commun. Soil Sci. Plant Anal. 2020, 51, 1065-1077. [CrossRef]

32. Santos, R.O.D.; Franco, L.B.; Silva, S.A.; Sodré, G.A.; Menezes, A.A. Spatial variability of soil fertility and its relation with cocoa yield. Revista Brasileira de Engenharia Agrícola e Ambiental 2017, 21, 88-93. [CrossRef]

33. Bian, Z.F.; Yu, H.C.; Hou, J.; Mou, S.G. Influencing factors and evaluation of land degradation of 12 coal mine areas in Western China. J. China Coal Soc. 2020, 45, 338-350. [CrossRef]

34. Liu, Y.; Lei, S.G.; Cheng, L.S.; Cheng, W.; Bian, Z.F. Effects of soil water content on stomatal conductance, transpiration, and photosynthetic rate of Caragana korshinskii under the influence of coal mining subsidence. Acta Ecol. Sin. 2018, 38, 3069-3077. [CrossRef]

35. Pansu, M.; Gautheyrou, J. pH Measurement; Springer: Berlin/Heidelberg, Germany, 2006, ISBN 3540312102.

36. Wu, Y.; Xu, N.; Wang, H.; Li, J.; Zhong, H.; Dong, H.; Zeng, Z.; Zong, C. Variations in the diversity of the soil microbial community and structure under various categories of degraded wetland in Sanjiang Plain, northeastern China. Land Degrad. Dev. 2021, 32, 2143-2156. [CrossRef]

37. Pei, L.; Xiao, J.; Sun, L. The effects of reclaimed water irrigation on the soil characteristics and microbial populations of plant rhizosphere. Environ. Sci. Pollut. Res. 2021, 17570-17579. [CrossRef]

38. Zhang, W.; Zhao, J.; Pan, F.; Li, D.; Chen, H.; Wang, K. Changes in nitrogen and phosphorus limitation during secondary succession in a karst region in southwest China. Plant Soil 2015, 391, 77-91. [CrossRef]

39. Zhao, Y.B.; Lei, S.G.; Liu, Y. Spatial variability and influencing factors of soil nutrients in Shengli Mining Area. Soils 2020, 52, 356-364. [CrossRef]

40. Razali, N.M.; Wah, Y.B. Power comparisons of shapiro-wilk, kolmogorov-smirnov, lilliefors and anderson-darling tests. J. Stat. Model. Anal. 2011, 2, 21-33. Available online: https://www.researchgate.net/publication/267205556 (accessed on 25 February 2022).

41. Gao, F.J.; Ma, Q.L.; Han, W.W.; Shan, P.M.; Zhou, J.; Zhang, S.L.; Zhang, Z.M.; Wang, H.Y. Spatial variability and distribution pattern of soil organic matter in a mollisol watershed of China. Environ. Sci. 2016, 37, 1915-1922. [CrossRef]

42. Wang, G.; Li, J.; Ravi, S.; Theiling, B.P.; Sankey, J.B. Fire changes the spatial distribution and sources of soil organic carbon in a grassland-shrubland transition zone. Plant Soil 2019, 435, 309-321. [CrossRef]

43. Wang, G.; Li, J.; Ravi, S.; Dukes, D.; Gonzales, H.B.; Sankey, J.B. Post-fire Redistribution of Soil Carbon and Nitrogen at a Grassland-Shrubland Ecotone. Ecosystems 2019, 22, 174-188. [CrossRef]

44. Cao, Q.; Li, J.; Wang, G.; Wang, D.; Xin, Z.; Xiao, H.; Zhang, K. On the spatial variability and influencing factors of soil organic carbon and total nitrogen stocks in a desert oasis ecotone of northwestern China. Catena 2021, 206, 105533. [CrossRef]

45. Wang, J.; Ouyang, J.; Zhang, M. Spatial distribution characteristics of soil and vegetation in a reclaimed area in an opencast coalmine. Catena 2020, 195, 104773. [CrossRef]

46. Getnet, T.; Mulu, A. Assessment of soil erosion rate and hotspot areas using RUSLE and multi-criteria evaluation technique at Jedeb watershed, Upper Blue Nile, Amhara Region, Ethiopia. Environ. Chall. 2021, 4, 100174. [CrossRef]

47. Li, Q.H.; Zhang, J.; Wang, L.; Wang, Y.P. Desiccation and Nutrient Status of the Soil in Apple Orchards in Hilly-Gully Region of the Loess Plateau. Acta Pedol. Sin. 2018, 55, 503-514. [CrossRef]

48. Zhang, J.Q.; Gong, J.; Liu, D.Q. Spatial distribution characteristics of the storages of soil organic Carbon and total Nitrogen in the Bailongjiang Watershed of Gansu. Chin. J. Soil Sci. 2018, 49, 23-30. [CrossRef]

49. Gao, X.; Xiao, Y.; Deng, L.; Li, Q.; Wang, C.; Li, B.; Deng, O.; Zeng, M. Spatial variability of soil total nitrogen, phosphorus and potassium in Renshou County of Sichuan Basin, China. J. Integr. Agric. 2019, 18, 279-289. [CrossRef]

50. Yan, P.; Lin, K.; Wang, Y.; Tu, X.; Bai, C.; Yan, L. Assessment of Influencing Factors on the Spatial Variability of SOM in the Red Beds of the Nanxiong Basin of China, Using GIS and Geo-Statistical Methods. ISPRS Int. J. Geo-Inf. 2021, 10, 366. [CrossRef]

51. Hua, D.; Li, J.; Xu, Y. Influence of Topographical Factors on Spatial Distribution Characteristics of Soil Nutrients in Qinba Mountain Area. IOP Conf. Ser. Earth Environ. Sci. 2020, 558, 32025. [CrossRef]

52. Maede, F.; Seyed, F.A. Effects of wind erosion on soil organic carbon dynamics and other soil properties: Dejgah catchment, Farashband County, Shiraz Province, Iran. Afr. J. Agric. Res. 2013, 8, 4452-4459. [CrossRef]

53. Liu, Y. Study on Guided Restoration of Damaged Vegetation in Semi-Arid Coal Mine Area. Ph.D. Thesis, China University of Mining and Technology, Xuzhou, China, 2020.

54. Wang, C.; Wang, X.; Liu, D.; Wu, H.; Lü, X.; Fang, Y.; Cheng, W.; Luo, W.; Jiang, P.; Shi, J.; et al. Aridity threshold in controlling ecosystem nitrogen cycling in arid and semi-arid grasslands. Nat. Commun. 2014, 5, 4799. [CrossRef] [PubMed] 